\title{
Experimental Study of the Effective Indexes of Refraction of Ethyl Red in Ethanol Solution as a Nonlinear Optical Material
}

\author{
Shengwen $\mathrm{Qi}^{1,2,3, \mathrm{a}}$ and Hongguang $\mathrm{Lu}^{4, \mathrm{~b}}$ \\ ${ }^{1}$ School of Mathematics, Physics and Information Science, Zhejiang Ocean University, Zhoushan \\ 316022, China \\ ${ }^{2}$ Key Laboratory of Oceanographic Big Data Mining \& Application of Zhejiang Province, Zhoushan, \\ Zhejiang 316022, China \\ ${ }^{3}$ Shandong Provincial Key Laboratory of Functional Macromolecular Biophysics, Dezhou 253023, \\ China \\ ${ }^{4}$ Affiliated Hospital, Guiyang Medical University, Guiyang 550002, China \\ a qi1963@163.com, b hongguanglu@yahoo.com
}

Keywords: ethyl red, nonlinear, effective indexes of refraction.

\begin{abstract}
With the Z-scan method, the nonlinear optical properties of the sample of Ethyl red (ER) in ethanol solution (in which the content of ER is $1 \%$ by weight) were measured using the lasers of three wavelengths $(441.6 \mathrm{~nm}, 535 \mathrm{~nm}$ and $633 \mathrm{~nm})$ respectively. As a result, the effective indexes of refraction $\mathrm{n} 2$ of $\mathrm{ER}$ at the three wavelengths are in the range from $1.35 \times 10-10$ to $5.44 \times 10-9 \mathrm{~m} 2 / \mathrm{W}$; $\mathrm{n} 2$ at $535 \mathrm{~nm}$ is the maximal and about 30 times that at $633 \mathrm{~nm}$. The results show that the ER has a potential application value in optical limiting or in the field of fast response.
\end{abstract}

\section{Introduction}

In recent twenty or more years, azo dye has become attractive material and been applied in many aspects, such as polarized photo-induced anisotropy and nonlinear optics effect [1-6], because of its unique optical properties. Azo dye has good photo-thermal stability, dissolvability and easily prepared virtue, so it can be used as a kind of novel storage medium. Most importantly, its structure can be modified in order to change its absorption band according to demands. Its potential application is to work as novel optical limiter for its nonlinear optical effect. The character of its molecular structure is double bonds " $\mathrm{N}=\mathrm{N}$ " between the two phenyls. By light illumination, azo dye can generate isomerization reaction between trans and cis, which induces photochromic effect and photoinduced birefringence effect [7-9]. The transition between trans and cis, which depends on the wavelength of irradiation light, is reversible and can result in the change of the absorption coefficient. In this paper, the nonlinear optical properties of ER are measured.

\section{Preparation and spectrum of the sample}

The molecular structure of ER is shown in Fig. 1. The ER solution is made up as follows: ER is dissolved in ethanol; the content of ER in ethanol is $1 \%$ by weight. Some threads are fixed between a pair of clean glass slides to control the thickness of the film. The solution is spread on the glass slide and a film between the two slides of glass shapes. The edges of the two slides adhere to each other by fluid sealant. The film thickness is $80 \mu \mathrm{m}$. In order to measure the absorption spectrum, the solution is diluted (the weight ratio is about 1\%o). The peak of the measured absorption spectrum is 460nm (Fig. 2). 


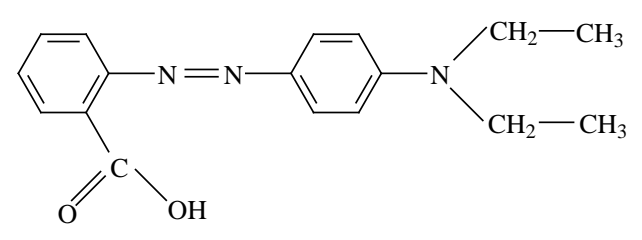

Fig. 1. Molecular structure of ER.

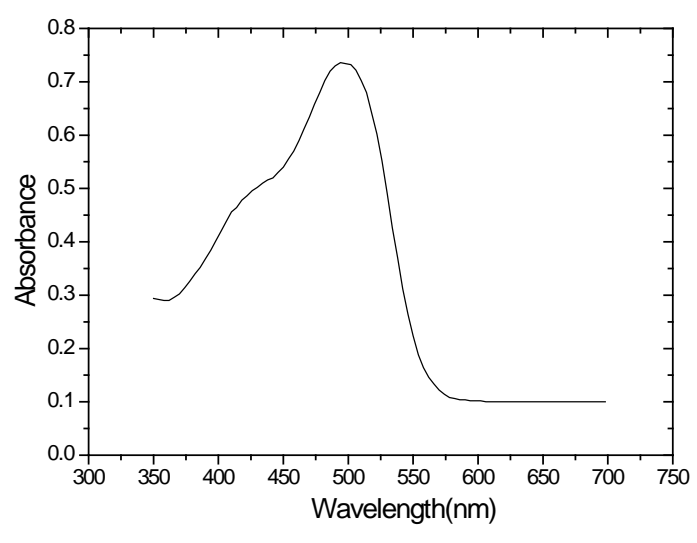

Fig. 2. Spectrum of ER in ethanol solution.

\section{Experiment of Z-scan}

Z-scan can be used for determining the effective index of refraction $n_{2}$ of cubical nonlinear optical materials and the refractive index change $\Delta n$ [10]-[11]. In our experiments, the condition $\pi \omega^{2} / \lambda>L$ is always satisfied for an optical thin sample, so $\Delta n$ and $n_{2}$ can be calculated by [12]

$$
\Delta n=\frac{\lambda}{2 \pi} \frac{\alpha}{1-e^{-\alpha L}} \frac{\Delta T_{P-V}}{0.406(1-s)^{0.25}}
$$

$$
n_{2}=\frac{\pi \omega^{2}}{2 P} \Delta n
$$

where $\lambda$ is the free space wavelength of the illumination beam, $\alpha$ is the effective absorption coefficient, $L$ is the thickness of the sample, $\Delta T_{\mathrm{P}-\mathrm{V}}$ is the normalized transmittance difference between maximum and minimum transmittances, $s$ is the linear transmittance, $P$ is the power of the Gaussian beam, and $\omega$ is the waist radius of the illumination beam inside the film.

Using He-Cd laser $(\lambda=441.6 \mathrm{~nm})$ as the probe beam, for ER ethanol film, the measured results of Z-scan are shown in Fig. 3. The data in Fig. 3(a) and Fig. 3(b) are the measured results using closed and open aperture respectively. The curves in Fig. 3(a) and Fig.3(c) are normalized to their values when the sample is located in the focus position. In order to eliminate the effect of intensity-dependent transmittance of the sample on the measured results, the data in Fig. 3(a) is divided by the corresponding data in Fig. 3(b) and the corrected data is shown in Fig. 3(c). From Fig.3(c), we can get $\Delta T_{\mathrm{P}-\mathrm{V}}=0.956$. Since $L=0.082 \mathrm{~mm}, P=4 \mathrm{~mW}, s=0.5, \omega=0.027 \mathrm{~mm}$ and $\alpha=12.2 \mathrm{~mm}^{-1}$, so that we obtain $\Delta n=-0.0038$ and $n_{2}=-1.08 \times 10^{-9} \mathrm{~m}^{2} \mathrm{~W}^{-1}$. 
Using the laser $(\lambda=535 \mathrm{~nm})$ as the probe beam, the results of Z-scan using closed and open aperture, and the corrected results are shown in Fig.4 respectively. From Fig.4(c), we can get $\Delta T_{\mathrm{P}-\mathrm{V}}=0.545$. Since $L=82 \mu \mathrm{m}, P=4 \mathrm{~mW}, s=0.5, \omega=0.045 \mathrm{~mm}$ and $\alpha=15.1 \mathrm{~mm}^{-1}$, and we obtain $\Delta n=-0.0029$ and $n_{2}=-2.28 \times 10^{-9} \mathrm{~m}^{2} \mathrm{~W}^{-1}$.

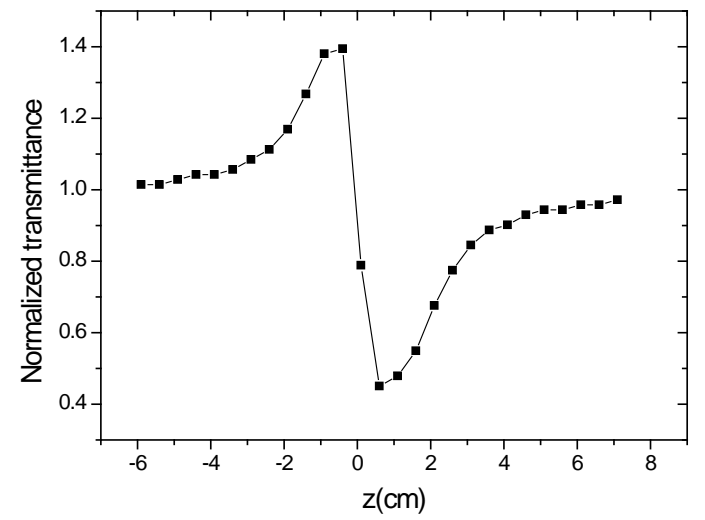

(a)

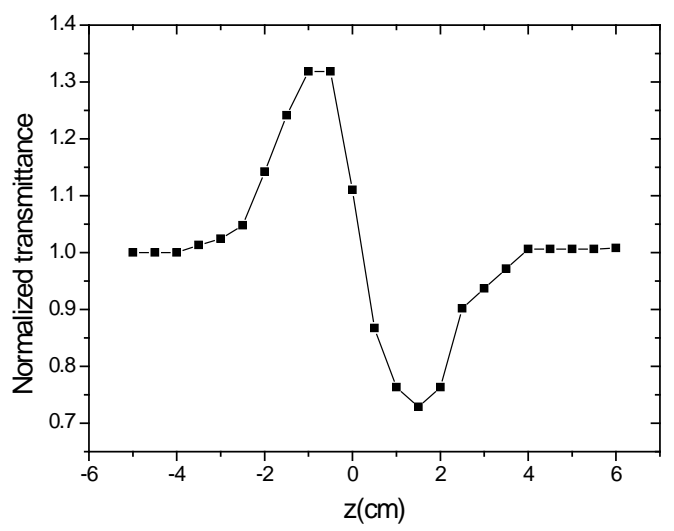

(a)
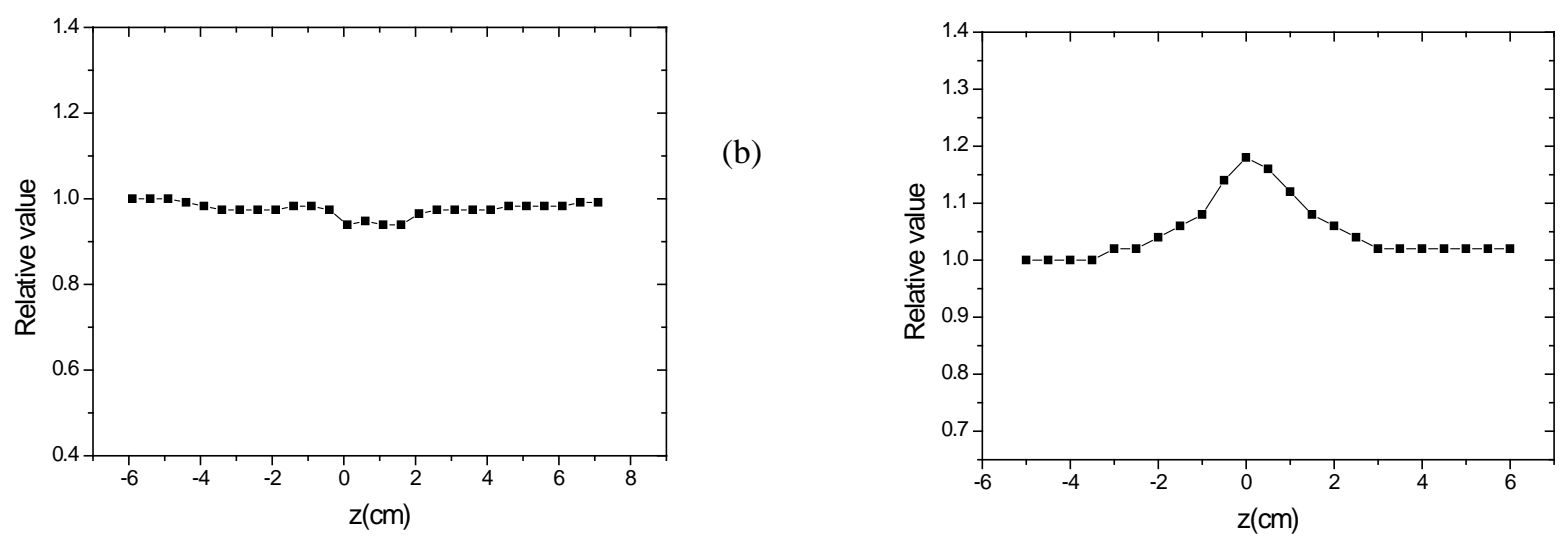

(b)

(b)
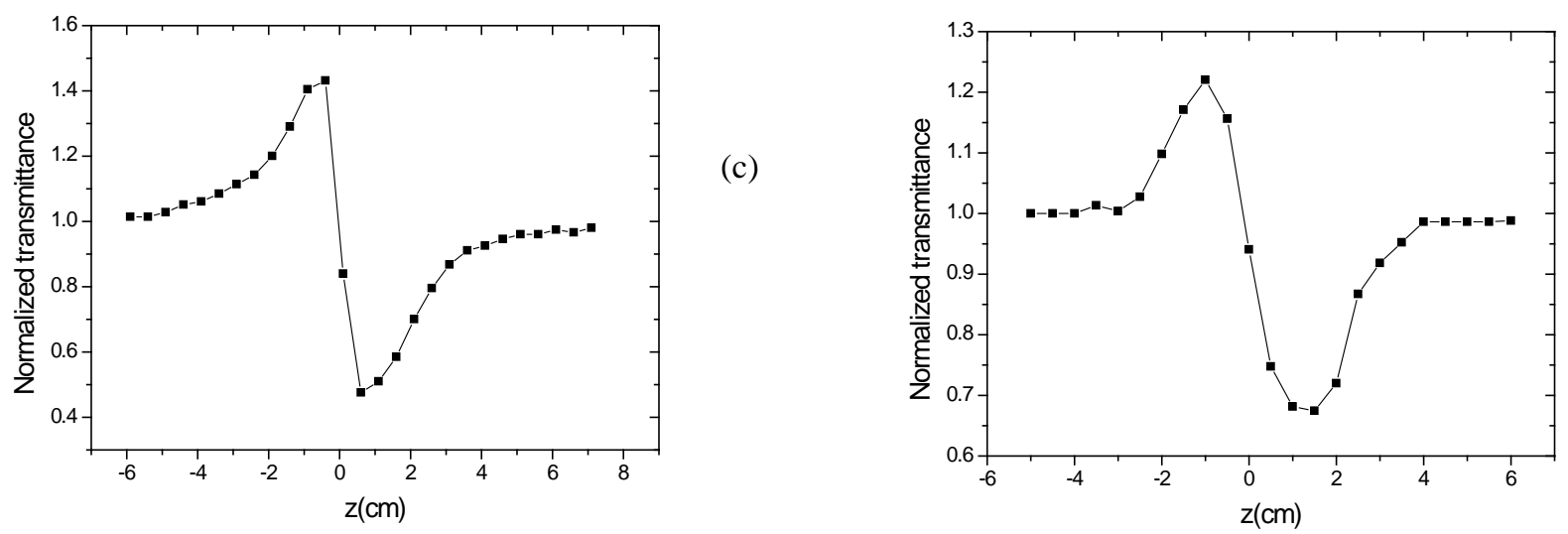

(c)

Fig. 3. Normalized Z-scan transmittance of the ER ethanol film by using the 433nm laser: (a) closed-aperture Z-scan; (b) open-aperture Z-scan; (c) divided Z-scan.

(c)

Fig. 4. Normalized Z-scan transmittance of the ER ethanol film by using the 535nm laser: (a) closed-aperture Z-scan; (b) open-aperture Z-scan; (c) divided Z-scan.

Similarly, when He-Ne laser $(\lambda=633 \mathrm{~nm})$ serves as the probe beam, the results of Z-scan using closed and open aperture, and the corrected results are shown in Fig.5 respectively. From Fig.5(c), we can get $\Delta T_{\mathrm{P}-\mathrm{V}}=0.06$. Since $L=82 \mu \mathrm{m}, P=4 \mathrm{~mW}, s=0.5, \omega=0.037 \mathrm{~mm}$ and $\alpha=3.75 \mathrm{~mm}^{-1}$, and we obtained $\Delta n=-2.51 \times 10^{-4}$ and $n_{2}=-1.35 \times 10^{-10} \mathrm{~m}^{2} \mathrm{~W}^{-1}$. 
As a result, the intensity dependent index $n_{2}$ of ER is determined to be in the range from $10^{-10}$ to $10^{-9} \mathrm{~m}^{2} / \mathrm{W}$, and $n_{2}$ at $535 \mathrm{~nm}$ is the maximal, $5.44 \times 10^{-9} \mathrm{~m}^{2} \mathrm{~W}^{-1}, \quad n_{2}$ at $441.6 \mathrm{~nm}$ takes second place and $n_{2}$ at $633 \mathrm{~nm}$ is the minimal. $n_{2}$ at $535 \mathrm{~nm}$ is about 30 times that at $633 \mathrm{~nm}$ (Fig. 6).

\section{Conclusion}

The absorption spectrum of ER in ethanol solution is obtained. With the Z-scan method, the nonlinear refractive index and the change of refractive index of ER are measured by using the lasers of $441.6 \mathrm{~nm}, 535 \mathrm{~nm}$ and $633 \mathrm{~nm}$ respectively. The results indicate that ER sample has a larger optical nonlinearity compared with other optical materials: $n_{2}$ of the sample is $-2.28 \times 10^{-9} \mathrm{~m}^{2} \mathrm{~W}^{-1}$ at $535 \mathrm{~nm}$, while other nonlinear materials such as the poly (phenylacetylene) and poly (p-methoxyphenylacetylene) have $n_{2}=6 \times$ $10^{-22} \mathrm{~m}^{2} \mathrm{~W}^{-1}$ and $n_{2}=1.1 \times 10^{-21} \mathrm{~m}^{2} \mathrm{~W}^{-1}$, respectively [13]; the averaged $n_{2}$ values for crystals $\mathrm{LN}: \mathrm{Mg}$ and potassium titanyl orthophosphate are $2.0 \times$ $10^{-19} \mathrm{~m}^{2} \mathrm{~W}^{-1}$ and $1.2 \times 10^{-19} \mathrm{~m}^{2} \mathrm{~W}^{-1}$, respectively [14]; for eosin doped in a polymer film, $n_{2}=5.58$ $\times 10^{-16} \mathrm{~m}^{2} \mathrm{~W}^{-1}[15]$.

The lasers of $441.6 \mathrm{~nm}, 535 \mathrm{~nm}$ and $633 \mathrm{~nm}$ can all induce thermal self-defocusing effects in ER solution, so we can consider the effects may occur when the illumination wavelengths are in the range from $441.6 \mathrm{~nm}$ to $633 \mathrm{~nm}$. Comparatively, many other materials including methyl orange, congo red and mercury dithizonate which were used in our experiments, present thermal self-defocusing effects only on condition that irradiating lasers have some specific wavelengths located in the narrow absorption band of the materials. Namely, the range of wavelengths that has the thermal self-defocusing effects on ER is wider [16]-[19].

Besides, we found that the ER doped PMMA film shows photochromism no sooner than it is irradiated by the $\mathrm{CW}$ laser of $535 \mathrm{~nm}$. The response time is very short $(5-10 \mathrm{~ms})$ and when the irradiation is blocked, the sample recovers promptly (0.1-0.2s). Comparatively, corresponding times for methyl orange and mercury dithizonate are from tens to hundreds of seconds. So, ER can be used potentially in the field of fast response.

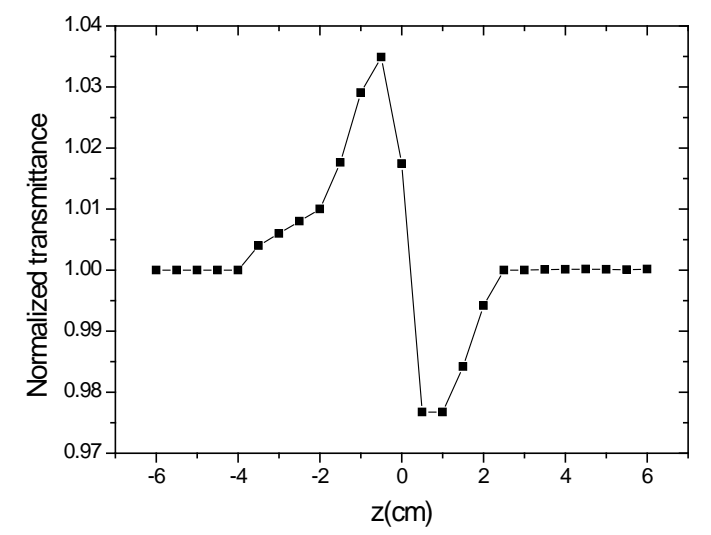

(a)

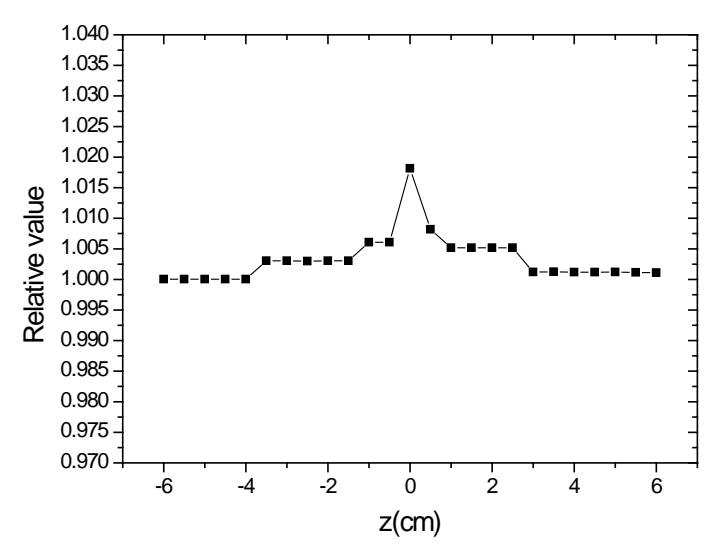

(b)

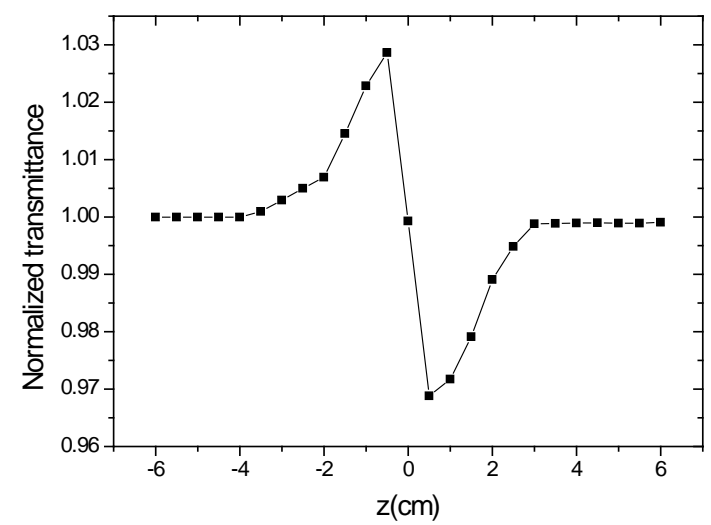

(c)

Fig. 5. Normalized Z-scan transmittance of the ER ethanol film by using the 633nm laser: (a) closed-aperture Z-scan; (b) open-aperture Z-scan; (c) divided Z-scan. 


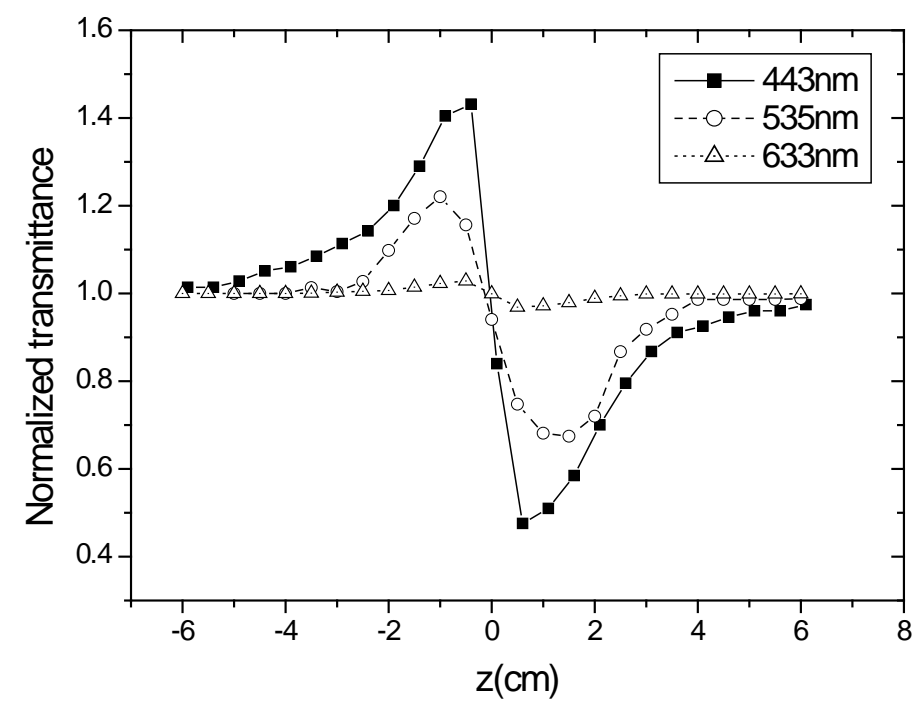

Fig. 6. Divided Z-scan curves by using the lasers of $433 \mathrm{~nm}, 535 \mathrm{~nm}$ and $633 \mathrm{~nm}$.

\section{Acknowledgments}

This work is supported by the Natural Science Foundation of Shandong (ZR2014FL028) and the National Natural Science Foundation of China (No.11305141).

\section{References}

[1] Kaino T. and Tomaru S.: Adv Mater. Vol. 5 (1993), p. 172

[2] P. Rochon, J. Gosselin: Appl. Phys. Lett. Vol. 60 (1992), p. 4

[3] T. Todorov, L. Nikolova and N. Tomova: Appl. Opt. Vol. 23 (1984), p.4309

[4] V. P. Pham, G. Manivannan and R. A. Lessard: Appl. Phys. A Vol. 60 (1995), p. 239

[5] C. Egami, Y. Suzuki, T. Uemori, O. Sugihara and N. Okamoto: Opt. Lett. Vol. 22 (1997), p. 1428

[6] Shaoping Bian and Mark G. Kuzyk,: Opt. Lett. Vol. 27 (2002), p. 1761

[7] Prasad P N: Polymer Vol. 32 (1991), p. 1746

[8] Ramos R, Petersen P M and Johansen P M: J. Appl. Phys. Vol. 81 (1997), p. 7728

[9] L. Nikolova, P. Markovsky and N. Tomova: J. Modern Optics Vol. 35 (1988), p. 1789

[10] M. Sheik-Bahae, A. A. Said and E. W. Van Stryland: Opt. Lett. Vol. 14 (1989), p. 955

[11] Q. W. Song and C. Zhang: Opt. Lett. Vol. 18 (1993), p. 775

[12] S. Qi, X. Yang, C. Zhang, R. Lu, K. Chun, J. Tian, J. Xu and Q. Wu: J. Modern Optics Vol. 51 (2004), p. 1671

[13] Falconieri M., D Amato R. and Furlani A.: Synthetic Met. Vol. 124 (2001), p. 217

[14] H. P. Li, C. H. Kam, Y. L. Lam and W. J: Opt. Mater. Vol. 15 (2001), p. 237

[15] Fei H.: Physics Vol. 23 (1994), p. 178

[16] Xu X., Ming H. and Wang P.: J. Opt. A: pure appl. Optics Vol. 4 (2002), p. L5 
[17] Wang G. and Gan F.: Mater. Lett. Vol. 43 (2000), p. 6

[18] S G Cloutier, D A Peyrot, T V Galstian and R A Lessard: J. Opt. A: Pure Appl. Opt. Vol. 4 (2002), p. S228

[19] L. Zhang, Z. Cai and Valerica Ninulescu: Chinese Journal of Polymer Science Vol. 19 (2001), p. 255 